\title{
A Lecturer and New Quality of Russian Professional Education
}

\author{
Svetlana Urievna Zalutskaya \\ Svetlana Viktorovna Panina \\ Galina Egorovna Zhondorova \\ VarvaraVasilievnaYakovleva
}

M. K. Ammosov North-Eastern Federal University, Russian Federation, Yakutsk, Belinski street, 58, 677000

Email: zs-saha@mail.ru

Doi:10.5901/mjss.2015.v6n3s3p409

\begin{abstract}
This article discusses the quality of teaching in higher education in the contemporary socio-economic conditions, analyzes the concept of "quality education" customary in the European educational space. A comparison of certain aspects of the European and Russian education suggests similarity of the major challenges in the modern world in training qualified personnel. Future professionals should be prepared for the creative approach to dealing with professional and personal issues, be ready for unassisted learning and development, productive communication, and for a dialog with other people. The quality of training and the level of competence of specialists in many ways depends on the abilities and competence of teachers. Therefore, the education community in Europe and Russia sets high requirements for the quality of teaching in higher education institutions. The quality of teaching at a higher educational institution is influenced by many factors. The article highlights factors such as availability of effective methods of teaching, atmosphere of cooperation, a system of leadership in scientific and practical activities of the student community. The authors describe the requirements and criteria for assessing the quality of a lecturer, which were developed in the North-Eastern Federal University (Russia). One of the tools for monitoring the quality of teaching in a discipline used in order to obtain feedback from students is given as an example. The authors describe the form of interaction between the university and the employers who are involved in the development of curricula and provide management practice for students in the form of mentorship. The conclusion is that there is a demand for sharing the experience between the counterparts at Russian and European universities regarding improving the quality of teaching and maintaining the best pedagogical traditions in terms of innovation processes in the global education system.
\end{abstract}

Keywords: education, lecturer, quality, monitoring, criteria.

\section{Introduction}

"Nowadays, "Educated Europe" is widely recognized as an irreplaceable factor for social and human development. It is a necessary component to consolidate and enrich the citizenship in the European Union, capable of giving its citizens the necessary knowledge to confront the challenges of the new millennium, together with the awareness of the community values and the belonging to a common socio-cultural space. The importance of education and educational cooperation in the development and strengthening of stable, peaceful, and democratic societies is generally acknowledged paramount..." (Raik \& Raud, 2013). The Professional European Community is convinced that the main problem of higher education is the poor quality of training specialists at higher educational institutions. These problems arose for historical reasons, different experience in this field, traditions, and approaches to the organization of the learning process.

The basic principles of international standards, which are the basis for the formation of the university's quality policy in the modern market conditions, are the orientation to customer's interests, involvement of staff and students in the quality management activities and continuous improvement of the quality management system, mutually beneficial relationships with suppliers, customers, educational services, etc. (Federal State Educational Standard, 2001). The criteria for assessing the quality are to correlate with the regulatory requirements for quality and take into account the peculiar features of the in-house quality standard. At the governmental level, the quality of training specialists at universities is assessed in accordance with the requirements of the process, the Certification and Accreditation. The training quality is considered a kind of an integral issue, the integrative properties of which are not a mere sum of its components. 
In this regard, after the introduction of the ISO 9000 international standards and the Total Quality Management principles (TQM), this work intensified in the leading higher educational institutions of Russia (Shkarina \& Kapinus, 2013), including federal universities, which were to head the process of integration into the international educational space, and which were the leaders by the professional education quality.

Given this factor, the establishment of new federal universities in Russia "is focused on new quality of training of highly skilled specialists through the use of modern educational technology for integrated socioeconomic development of the region. The Ammosov North-Eastern Federal University (NEFU) in 2010, the leading scientific, educational, and cultural center in the north-east of Russia with a developed innovative scientific sociocultural infrastructure, was established to provide qualified higher education compliant with the world standards, integrate science, education, and industry, develop high technology and modernize the economic and social spheres of the region" (Panina, 2014 ).

With account of the peculiarities of socioeconomic development of the North-East of Russia, the federal institution is to train highly qualified specialists in accordance with the needs of the innovation-oriented economy, its priority sectors in the long term, science, technology, education, culture, and social services. On this basis, the North-Eastern Federal University has identified its mission as "to cultivate competitive professionals by carrying out research and implementing innovations to develop a sustainable, socially developed circumpolar region, ensuring high quality of life, preservation and development of the culture of the peoples of the North-East of Russia. Formation of multicultural outlook and personal self-determination in NEFU should become a part of the system of lifelong education in the university, aimed to keep forming the personality during his whole life" (Mordovskaya \& Panina, 2012).

\section{Literature Review}

Specialists of higher school focus on training. The basic provisions of the Bologna Process emphasize that improvement of the education quality is a priority for the internationalization of education: "Quality is the main condition for trust, relevance, mobility, compatibility, and attractiveness in the European Higher Education" (The Bologna Process: the Growing Dynamics and Diversity of 2002). However, the problem is what is meant by quality education. In the scientific literature, there is a variety of approaches to the concept interpretation. Each of the existing definitions discloses a particular aspect of quality education. For example, parents of students associate the quality of education with several individuals in the education process (Ratings in education: from single practices to cultural decisions in 2014). For learners, the quality can be described as in terms of ratings, the attractiveness of the content of school subjects and teaching or usefulness of education to get a job (Waldman, 2011). Quality in relation to a teacher is associated with "the quality of the curriculum, teaching methods, competitiveness of graduates in the labor market, the level of competence needs, and the ability to engage in teaching activities, research activity, presence of a scientific school" (Altukhova \& Altukhov, 2010). Minister of Education and Science of the Russian Federation Dmitry Livanov in an interview to the general public determined "quality" as the priority concept of the modern Russian education and characterized it as a compliance of all components of the educational process with state standards (Livanov, 2013).

In this study, we believe students to be the first consumers of educational services. Based on their educational needs (Efimov, 2010) and with account of employers' demands, higher education institutions of the CIS countries develop and apply in-house quality assurance system of training.

\section{Method}

\subsection{Pressing issues of quality education in Europe and Russia}

The necessity to address the issue of quality at a new stage of European Community's development is confirmed by results of scientific and practical activities organized by representatives of universities from different countries for solving critical issues related to the effectiveness of teaching and learning. In particular, we are talking about the International Scientific Conference on the pressing subject: "Higher Education - Higher Level Learning?", which was held in the early 2013 in Tallinn (Estonia). According to the organizers, the event was aimed at revealing the lecturers' ability to combine research and teaching harmoniously, the level of skill of lecturers and its compliance with modern quality standards. Besides, the issues of influence of lecturers on the basic processes in the sphere of professional education and their capabilities in the development of students in higher education and the improvement of the whole education system and society in general were in the focus of the conference.

As seen, the quality of teaching in higher school and lecturers providing (or not providing for any reasons) the quality in the circumstances of integration of their research and practice of teaching students is in the center of the 
problem. The higher the professionalism of a teacher, the better the quality of higher education - this rule has been the subject for the educators of the Baltic countries and the countries of the Western and Eastern Europe. These issues are topical for the Russian system of higher education, too.

During his career, a modern lecturer encounters multiple problems, which can be conditionally broken up into three groups. They are: 1) How to organize yourself and your research and teaching activities? 2) How to organize students and direct them to productive learning? 3) How to combine effectively your time-consuming scientific research and the educational efforts? A novice is not always able to address these issues without assistance and to build up his business career.

\subsection{Monitoring the quality of a teacher in the North-Eastern Federal University}

A useful solution is an education community organized as per the requirements of international quality standards to monitor continuously the results of each teacher in higher school. For example, in the North-Eastern Federal University, the following assessment criteria of teaching quality are used:

- conformity of the amount and content of training to the position and regulations of the institution;

- conformity of the subjects taught to the educational standards (programs, thematic plans);

- promotion of the educational, professional, and personal achievements of students;

- profundity and the progressiveness of sci-tech and professional practical information on the teaching courses;

- logic and accuracy of the provided information;

- expediency of choice and appropriateness of methods and forms of the students' educational activities organization;

- sequence in the implementation of the system requirements and objectivity in assessing the results;

- establishment of contact;

- tact in maintaining procedures necessary for specific types of training classes;

- professional speech, its expression, optimal rate, comprehensibility, ability to make necessary entries;

- creativity in organizing different types of educational activities for students;

- display of professional and pedagogical individuality.

- Also the quality of the research activities of teachers is assessed:

- latitude and orientation of the scientific activity of a lecturer;

- conformity of the amount and the genre of scientific work with the status and position in the educational institution;

- the nature of participation in scientific events and activities;

- the level of review, opposing, and other types of analysis of scientific works;

- competence in all kinds of scientific work;

- scientific productivity;

- scale and significance of the scientific work results;

- latitude and scope of application of research results;

- abidance by the norms of scientific ethics in publications and oral presentations;

- systematic nature and organization of scientific activity;

- effectiveness of management of students' research activities;

- the level of scientific independence;

The methodical work of lecturers is the subject of analysis:

- methodical productivity;

- conformity of the amount and genre of teaching and scientific-methodical work of a lecturer with the status and position in the educational institution;

- completeness of the scientific methods and methodological support of lectures held in the form of workshops and other forms of educational activities organization, including all kinds of self-study;

- the level of novelty and progressiveness of teaching materials used and recommended by a lecturer;

- completeness of teaching materials in terms of coverage of the modern level of science and practice's development;

- completeness of the implementation of didactic and psychological requirements for all kinds of methodological products;

- inclusion of modern educational and information technologies in the educational process;

- availability of teaching materials for learning by colleagues; 
- the extent of implementation of the teaching materials;

- regularity and frequency of updating and enriching the educational discipline;

- authorship to the lecturer's methodical system.

- Work for the community is another aspect of the analysis of teacher's quality at a Russian university. It is characterized by the following criteria:

- the amount of regular or one-time public activities;

- the number of awards and incentives;

- the extent of participation in public affairs and individual actions;

- initiation of public affairs and individual actions;

- professional orientation of the lecturer's public affairs;

- the frequency of public affairs for students or in association with students;

- $\quad$ the complexity in the waste of time and effort carried out socially significant activities.

\subsection{The student's and employer's role in assessing the teaching quality}

The conformity of the teaching staff of the university to the proposed requirements allows raising the level of professional competence and solving the problem of creating an innovative learning environment. It promotes disclosing the internal potential of both students and teachers as the subjects of the educational process. Another instrument for monitoring the quality of a lecturer is the so-called feedback system: assessment of the quality of teaching subjects studied by students. The assessment is carried out regularly and anonymously, which, however, does not exclude certain subjectivity of such monitoring. For example, students at the M.K. Ammosov North-Eastern Federal University after studying individual disciplines fill in the following form (a sample questionnaire):

Table 1. The sample questionnaire for students

\begin{tabular}{|c|c|}
\hline Significant indicators & Score (from 0 to 3) \\
\hline Proposed lecturer information is significant for the future professional work & \\
\hline $\begin{array}{l}\text { The lecturer formulates a clear purpose and a plan of academic work in accordance with the curriculum of the } \\
\text { course }\end{array}$ & \\
\hline The lecturer promotes the growth of the educational achievements of students by his teaching & \\
\hline New, modern scientific information is proposed in the classes & \\
\hline He presents the material clearly, logically reasoned and committed & \\
\hline The applied methods, the methods and forms of the teacher's work are expedient and effective & \\
\hline $\begin{array}{l}\text { The lecturer proposes and is consistently guided by his system requirements and criteria for assessing of } \\
\text { educational activities }\end{array}$ & \\
\hline The lecturer establishes the necessary contact and uses adequate methods of communication and interaction & \\
\hline The lecturer is tactful in the process of interaction with students & \\
\hline $\begin{array}{l}\text { The teacher's speech is professional, expressive, optimum in tempo and power of voice, easy to understand, } \\
\text { and allows enough time for making necessary entries }\end{array}$ & \\
\hline The lecturer stimulates creativity of students in independent and research activities & \\
\hline $\begin{array}{l}\text { The lecturer has his own individual style of teaching, which promotes the consolidation or interest in science } \\
\text { and the future professional work }\end{array}$ & \\
\hline $\begin{array}{l}\text { Would you like to meet this lecturer in the future (reading other disciplines as a research consultant in the } \\
\text { period of practice, the head of course or research work)? }\end{array}$ & \\
\hline $\begin{array}{ll}0- & \text { I don't agree with this statement, it is not true } \\
\text { 1- } & \text { Really, I can agree with this statement, although it is not always true } \\
\text { 2- } & \text { As a rule, it is true } \\
\text { 3- } & \text { This statement is fully and always true with regard to this lecturer }\end{array}$ & \\
\hline
\end{tabular}

Such complex research allows managers of the institution to analyze the reasons of deterioration of the education quality and provide timely scientific, methodological, educational, and organizational assistance to a lecturer. It provides the opportunity to address the issues of effective time management; attend thematic training courses, which are have no system and are oriented to the personal needs of a teacher; organize a head-master having sufficient pedagogical and methodological experience; exchange experience with lecturers teaching related core disciplines, and so on.

The system of relations with an employer who is actively involved in different lines of higher education is also an effective tool to regulate the quality of lecturers at European universities (Bulanova, 2012). For example, he becomes a 
co-developer of educational programs, curricula and training programs on his profile training, which through such interaction with the customer allows lecturers to carry out practical and theoretical training of students in the context of the professional challenges they will face in their future production work. Also, an employer interested in hiring highly qualified personnel becomes a partner of the organization of students and actively cooperates with the leaders of this practical training on the part of the university stating the expected results to the students.

\subsection{Mentoring and the quality of students' practical training}

Monitoring the activities of practical teachers, study of their diaries, final conferences, conversations, surveys of students assume the invaluable role of an employer in the skills enrichment for future professionals. Organization of educational and industrial practical training helps correct professional motivation of students, efficiently adapt to the new social and professional roles, promote awareness of the importance of theoretical knowledge, effectively influence on the creative personality, and most importantly - focus on each student's future professional self-development regardless of his future career.

Cooperation of an educational institution with an employer is part of the mentoring system, under which universities in Estonia, for example, provide primary qualified mentoring to students. The concept of a "mentor" in the American Heritage Dictionary of the English Language, according to researcher S. Michaels, means "a wise and trusted counselor or teacher who wants to share their own experiences" (Kolodkina, 2010). This consultant/mentor should be properly trained under a higher school mentoring program, familiarize himself with the qualification requirements of the specific profile of the bachelor's and master's degrees, form an idea and learn the skills to monitor the professional competencies of students in the process of production practices. Only in this case, a mentor is invited to cooperate with the university and gets an opportunity to implement his basic functions: the pragmatic (observation, coaching, advice, criticism, partnership ...) and management (management, control ...) functions.

However, the role of a mentor can have a much broader interpretation as, for example, in Germany, where, according to the data of the online recruitment portal JobStairs, the leading German corporations are increasingly turning to mentoring as a means of competition for talented graduates (Gracheva, 2012). Companies conduct specialized seminars, thematic lectures, and advise students in modeling a business career at educational institutions. They provide support during the internship, assist in the process of writing the practical part of the bachelor's and master's qualification thesis, as well as provide a unique opportunity to develop in-house projects to familiarize students with the features of the organizational culture of the corporation. On this way, the system of mentoring promotes, on the one hand, the improvement of the quality of students' practical training, and, on the other hand, helps higher school teachers who do not have rich practical experience to manage the quality of theoretical bachelor's and master's training by making timely and necessary changes in the content and teaching methods of their discipline.

\section{Results and Discussion}

The teaching staff of a modern university should pay great attention to the methods of productivity and learning tools in the context of the specified problem.

The main requirements on the part of the European educational community are following:

- to stimulate students' interest in the studied subject and their desire to apply their knowledge and skills in life;

- to combine individual and group work of students in the learning process in order to implement the principles of cooperation;

- to use modern communication technology;

- to organize feedback from learners;

- to be emotional;

- to raise the level of students' trust in the learning process;

- to make the learning process available to all;

- to change the student's understanding of the subject, his creativity, philosophy, responsibility for the results of his work before the university and the society;

- $\quad$ to motivate students for self-learning, self-development, and self-fulfillment during the whole life;

- to make students successful and inspire them.

The basic principles of the lecturer training methods effectiveness are cooperation, interactivity, focus on the creative development of students. Their implementation is possible under the condition that educational activities are 
carried out in the university by scientific-pedagogical personnel capable of becoming the subject of the creative process, having creative personality, and meeting the following requirements:

- awareness that the lecturer is the determining factor in the education system and creative development of students;

- successful experience of pedagogical work, possession of qualities, such as maturity, emotional stability, commitment. "Creativity is the highest level of the creative initiative, the ability to creatively solve professional problems, innovation" (Klikunov, 2003);

- ability to create a developmental learning environment for creative development of students;

- special training on the theory of creativity and experience in practical activities;

- readiness of the teacher to work with different groups of students, differentiate the level of education, the level of intellectual and creative development, the existing general and specific abilities, aptitudes and interests;

- knowledge of and ability to apply the existing conceptual model of perfection of creative personality in the educational process;

- readiness to implement the principle of continuity between different levels of pre-university and post-graduate education; responsibility for the formation and development of creative abilities of personality;

- innovative capabilities: the ability to innovate, develop innovative learning models, etc.

The level of a teacher's competence in speech influences on the quality of training students in building a professional career. Competence in speech is a combination of knowledge and skills helping students to become proficient in speech, both dialogs and monologs, "good understanding of verbal and written speech, including the ability to produce and understand speech in any functional style" (Romanova \& Filippov, 2009). A university teacher creates his positive image during personal contacts with students and colleagues, which includes speech competence as a basic component. For a lecturer, regardless of his specialization in the professional sphere, the tongue is the most important tool of professional communication, an indispensable component of professionalism (Chernyak, 2011). Lecturer's speech is not only an integrative indicator of general human culture, but also recognition of the professional sphere. In addition to extensive knowledge in the taught discipline, education, and psychology, a lecturer must also be skilled in wording, possess competent expressive speech and the ability to form exemplary verbal behavior of future professionals. A mentor should be able to construct a dialog with his student. A teacher arouses curiosity by formulating a problem, awake cognitive interest of students. Speaking in search of an answer to the problem leads the student thought to the path of knowledge. The knowledge obtained as a result of this conversation (a dialog or debate) is emotional, which means that it is more effective in relation to studied concepts, rules, or any modes of action. Education in the "question-question" mode is the most appropriate for personal creative development (Vygotsky, 2005). It starts with the relevant problems of students to answer questions that could be based on the content of the subject

Such training is aimed at seeking answers, desiring to understand the logic of the study subjects, moving to the answer, understanding the answers contained in the training material. Therefore, the training is defined as a dialog-based interactive training (Korotaeva, 2012), during which there is interaction between the teacher and the student. Without contact with other people, there is no professional growth and training cooperation, which is one of the main problems of the modern educational process.

\section{Conclusion}

From the above, it can be concluded that training of a qualified teacher who meets the above requirements of a university is a process that requires time and experience. His scientific consultant helping young teachers to make an effective schedule of scientific activities, implement the results of his scientific research in educational activities, organize management of students' scientific work can play this role.

Apart from these problems of higher education in the sphere of professional education community of the EU countries, there are also issues of plagiarism and the quality of research in the format of theses; improvement of curricula and students' participation in the process; training of teachers; organization of student-centered learning in the circumstances of the education system standardization; teaching practices of certain disciplines; formation of students' responsibility for their learning process, their motivation for learning throughout life, etc.

Russian professors are particularly interested in the methods of solving the urgent issues of the higher school, which may be applied to the domestic educational system that is in process of continuing modernization and adaptation to the two-level training. The main target in the exchange of experience with European counterparts is to preserve the best traditions of national education while providing high quality education to enable Russian universities to compete in the EHEA. 


\section{References}

Altukhova, T.A., \& Altukhov, D.S. (2010). Indicators of the quality of education. Modern High Technologies, 7, pp. 232-234.

Bulanova, T.I. (2012). Innovations in the learning and teaching at higher educational institutions in the methods for calculating the payment of labor. Russian Entrepreneurship, 10(208), pp. 50-54.

Chernyak, V.D. (2011). Speech competence of a teacher in pedagogical discourse. Bulletin of the Chelyabinsk State University, 24(239)(Philology. Arts), Vol. 57, pp. 283-285.

Efimov, V.F. (2010). Humanistic aspects of differentiation of human needs as a condition of personal oriented education. Herald of the Adyghe State University. Ser .: Pedagogy and Psychology, 1(56), pp. 45-53.

Formation of the Future (Salamanca, 29-30 March 2001). The Bologna process: the increasing dynamics and diversity (documents of international forums and opinions of European experts) (2002, pp. 149-154). Moscow.

Gracheva, E.J. (2012). Features of mentoring novice teachers in the modern school of Germany. Offline Letters. Retrieved from http://www.emissia.org/offline/2012/1747.htm

Klikunov, N.D. (2003). Institutional change as a way of adapting the system of higher education to the current socio-economic conditions (pp. 123). ND Whooper, OryolUnivOrelGAU.

Kolodkina, L.S. (2010). Tutoring as a component of a multi-level support of students in the context of teaching practice variativnoj. Education and Society, 4, 22-27.

Korotaeva, E.V. (2012). Interactive Learning: Theory and Practice Training. Teacher Education in Russia, 3, pp. 171-174.

Livanov, D. (9 Sep. 2013). Quality of education - is the most important thing! Retrieved from http://smart-shkola.ru

Mordovskaya, A.V., \& Panina, S.V. (2012). Conceptual approaches to career guidance in the federal university. Teacher of XXI Century, 1.

Panina, S.V., Zalutskaya, S.Y., \& Grigorieva, V.V. (2014). Image making potential of higher educational establishment: Socio-cultural aspect. World Applied Sciences Journal, 29(70), pp. 56-860.

Raik, K., \& Raud, N. (2013). Quality of teaching and teaching style in an educational institution of higher professional education. Education in Estonia in the context of the European education system, Textbook (pp. 78-79). Narva: Raik \& Raud.

Ratings in education: from single to cultural practices solutions: Sat. materials (pp. 175, 2014). Moscow: the Publishing House of the Higher School of Economics.

Romanova, N.N., \& Filippov, A.V. (2009). Dictionary. Culture of verbal communication: ethics, pragmatics, psychology. Moscow, Flint, Science.

Shkarina, T.Y., \& Kapinus, E.V. (2013). Quality management system [electronic resource]: a tutorial (pp. 225). Vladivostok: The Far Eastern Federal University, School of Engineering.

State Standard of the Russian Federation. Quality management system. Fundamentals and vocabulary (pp.32, 2001). Moscow: State Standard of Russia.

The Bologna process: the growing dynamics and diversity of 2002.

Vygotsky, L.S. (2005). Psychology of Human Development. Moscow: The Meaning; Exmo.

Waldman, I.A. (2011). Key aspects of the quality of education: Lessons from International Experience. Education Management: Theory and Practice, 1, 17-62.

Website of the International Conference on "Higher Education - the highest level of education. Retrieved from primus.archimedes.ee/ conference. 